\title{
The Anaphylatoxin C3a Receptor Expression on Human M2 Macrophages Is Down-Regulated by Stimulating the Histamine H4 Receptor and the IL-4 Receptor
}

\author{
Susanne Mommert ${ }^{a} \quad$ Derya Aslan $^{\mathrm{a}} \quad$ Lisanne Ratz $^{\mathrm{a}} \quad$ Holger Stark $^{\mathrm{b}}$ \\ Ralf Gutzmer $^{\mathrm{a}}$ Thomas Werfel ${ }^{\mathrm{a}}$ \\ a Division of Immunodermatology and Allergy Research, Department of Dermatology and Allergy, \\ Hannover Medical School, Hannover, Germany; ${ }^{\mathrm{b}}$ Institute of Pharmaceutical and Medicinal Chemistry, \\ Heinrich Heine University, Duesseldorf, Germany
}

\section{Keywords}

M2 macrophages · Histamine $\mathrm{H} 4$ receptor $\cdot$ C3a receptor

\begin{abstract}
The anaphylatoxin C3a triggers inflammation by binding to its specific G-protein-coupled C3a receptor (C3aR). Since the number of $\mathrm{C} 3 \mathrm{aR}$, which is expressed on the cell surface, affects the response to $\mathrm{C} 3 \mathrm{a}$, we investigated the expression levels of C3aR on human M2 macrophages in allergic situations where high levels of the Th2 cytokine IL-4 and histamine are present in a local microenvironment. The histamine $\mathrm{H} 1$ receptor $(\mathrm{H} 1 \mathrm{R}), \mathrm{H} 2 \mathrm{R}$ and the $\mathrm{H} 4 \mathrm{R}$ mRNA expressions were induced or up-regulated during the differentiation process of $\mathrm{M} 2$ macrophages. The presence of histamine or agonists targeting the H1R, H2R and, in particular, the H4R during in vitro differentiation from monocytes to macrophages modified the M2 phenotype by regulating the macrophage differentiation markerCD68 and CD163 expressions. In addition, the C3aR expression was also down-regulated by ST-1006 during this process. Histamine and ST-1006 down-regulated the expression of $\mathrm{C} 3 \mathrm{aR}$ with different time kinetics on fully differentiated M2 macrophages. By analysing C3a-induced IL-6 mRNA expression, we observed a diminished response
\end{abstract}

\section{KARGER}

() 2018 S. Karger AG, Basel

E-Mail karger@karger.com

www.karger.com/jin to C3a in ST-1006-treated M2 macrophages when compared to un-treated cells. Expression of $\mathrm{C} 3$ was not affected by histamine, whereas IL-4 strongly down-regulated C3aR and C3 expressions. Our data suggests that down-regulation of C3aR expression by mediators present in allergic situations such as IL-4 or histamine has an anti-inflammatory impact by reducing the sensitivity to $\mathrm{C} 3 a$-induced down-stream signaling, thereby contributing to the regulation of local inflammatory responses in the skin.

(c) 2018 S. Karger AG, Basel

\section{Introduction}

Monocytes and macrophages are potent effectors bridging the innate and adaptive immune system by killing pathogens by phagocytosis and by producing inflammatory mediators in response to activating signals in their microenvironment. They also contribute to the resolution of inflammation by homeostatic clearance of cellular debris, thereby promoting tissue repair and remodelling. Monocyte-derived macrophages occupy within tissues a specific niche and differ in function depending on the local cytokine-chemokine milieu [1-3]. In lesional 
skin of patients with atopic dermatitis (AD), macrophages reside in the dermal mononuclear cell infiltrate. $\mathrm{AD}$ is one of the most frequent chronic inflammatory skin diseases, typically directed by an impaired skin barrier function and modifications of the immune system [4, 5]. At the early onset of AD, IL-4 and IL-13 represent the dominating cytokines, which in turn drive the polarization of macrophages into the M2a phenotype [6, 7]. Almost 4 decades ago, it was observed that the intensities of changes of complement and histamine levels in 15 patients with $\mathrm{AD}$ correlated with disease severity [8]. Moreover, intradermal injections of the anaphylatoxin C3a in human skin induced a dose-dependent wheal and flare reaction similar to the appearance of the classical response to histamine [9-11]. Since the anaphylatoxin fragments $\mathrm{C} 3 \mathrm{a}$ and $\mathrm{C} 5 \mathrm{a}$ induce chemotaxis as well as mediator release from basophils and mast cells, this effect could be attributed to the impact of histamine [10-12]. These events point to a potential crosstalk between complement factors and histamine in the course of allergic diseases. The complement system is an ancient major defence system whose activation occurs in a cascade-like fashion upon stimulation of pathogens or other danger signals. The pathway-specific activation (classical, lectin or alternative) of the third component $\mathrm{C} 3$ leads to the formation of $\mathrm{C} 3$ convertase, which cleaves C3 into the effector molecules $\mathrm{C} 3 \mathrm{a}$ and $\mathrm{C} 3 \mathrm{~b}$, which drive the microbial clearance [13]. The C3a receptor (C3aR), a G-protein-coupled receptor, specifically binds the anaphylatoxin fragment $\mathrm{C} 3 \mathrm{a}$. The $\mathrm{C} 3 \mathrm{aR}$ is functionally expressed on human keratinocytes [14], and on immune cells constituting the dermal infiltrate in AD skin, such as monocytes [15], dendritic cells (DCs) $[16,17]$ or activated T lymphocytes [18]. For this reason, the complement system seems to play a role in the pathogenesis of $\mathrm{AD}$. Histamine is a mediator of allergic reactions and is present in the skin of $\mathrm{AD}$ [19]. Important immunoregulatory effects exerted by histamine targeting 4 distinct histamine receptors (HR), which are differentially expressed on immune cells, had been described so far [20-22]. Macrophages as prominent innate immune cells express high amounts of $\mathrm{C} 3 \mathrm{aR}$ on their cell surface [23] and also the histamine- $\mathrm{H} 1-, \mathrm{H} 2$ - and $\mathrm{H} 4$ receptor mRNA [24]. We observed an induction or upregulation of $\mathrm{H} 1 \mathrm{R}, \mathrm{H} 2 \mathrm{R}$ and $\mathrm{H} 4 \mathrm{R}$ mRNA expressions by trend during the process of differentiation from monocytes to M2 macrophages. An influence of the Th2 cytokine IL-4, which is overexpressed in the acute phase of $\mathrm{AD}$ on the regulation of $\mathrm{C} 3 \mathrm{aR}$ or $\mathrm{C} 3$ expression, has not been described until now for human M2 macrophages. Therefore, we investigated whether IL-4 regulates C3aR and C3 expressions on fully differentiated M2 macrophages. Moreover, we investigated a functional role of histamine, in particular via $\mathrm{H} 4 \mathrm{R}$, on $\mathrm{C} 3 \mathrm{aR}$ expression in human monocyte derived M2 macrophages when histamine or the H4R agonist ST-1006 was supplemented to the medium during in vitro differentiation of monocytes to M2 macrophages. Finally, we stimulated fully differentiated M2 macrophages with histamine or different HR agonists targeting the H1R, H2R or H4R and analysed $\mathrm{C} 3 \mathrm{aR}$ and $\mathrm{C} 3$ expression levels.

\section{Materials and Methods}

\section{Isolation of Monocyte Derived Macrophages}

Residual blood samples from platelet apheresis disposables used for routine platelet collection and of regular anonymous healthy donors (buffy coats) served as source material for the isolation of human peripheral blood mononuclear cells (PBMCs). PBMCs were separated by density gradient centrifugation on lymphoprep (Fresenius Kabi Norge AS, Oslo, Norway). With a seeding density of $1 \times 10^{6}$ cells pro well, PBMCs were plated in a 24 well plate in Iscoves Medium supplemented with $\mathrm{AB}$ serum $(2.5 \% \mathrm{v} / \mathrm{v})$. To attach the monocytes, cells were incubated for $2 \mathrm{~h}$ at $5 \% \mathrm{CO}_{2}$ and $37^{\circ} \mathrm{C}$. Non adherent cells were removed by vigorously washing adherent cells 3 times with PBS. An appropriate amount of RPMI 1640, supplemented with $2 \mathrm{mM} \mathrm{L}$-glutamine, $100 \mathrm{mg} / \mathrm{mL}$ penicillin/streptomycin, $12 \mathrm{~mm}$ Hepes, and 5\% v/v FCS (PAN-Biotech, Aidenbach, Germany; all other media components from Biochrom, Berlin, Germany) and $10 \mathrm{ng} / \mathrm{mL}$ macrophage colony-stimulating factor (M-CSF; R\&D, San Diego, CA, USA) was added.

\section{Cell Culture, Differentiation of M2 Macrophages}

Cells were differentiated to M2 macrophages under different experimental settings:

1. Cells were cultured with M-CSF during the differentiation process to M2 macrophages.

2. Cells were cultured with M-CSF and in the presence of histamine or different HR agonists targeting the H1R, H2R or H4R during the differentiation process to M2 macrophages.

At day 5 , another $50 \%$ by volume of fresh medium containing the respective stimuli was added. At day 8 , the medium was completely changed. The differentiation process was controlled by analysing the expression levels of macrophage differentiation marker CD68 and the M2 marker CD163 at day 1,3, and 7 on cells which were cultured with M-CSF only. At day 10, CD68 and CD163 expression levels were assessed on all cells in the different experimental settings. C3aR was measured on macrophages, which were differentiated with MCSF only compared to histamine or ST-1006-treated cells.

Stimulation of Fully Differentiated M2 Macrophages

Additionally, M2 macrophages differentiated with M-CSF only were used for further experiments. Fully differentiated M2 macrophages appear as adherent cells with a prominent nucleus and multiple pseudopodia.

Assessment of $\mathrm{C} 3 \mathrm{aR}$ and $\mathrm{C} 3$ expression:

1. Fully differentiated M2 macrophages were stimulated with histamine or different HR agonists targeting the H1R, H2R or the 
H4R for different time periods as indicated in the respective Figures. Expression of $\mathrm{C} 3 \mathrm{aR}$ was analysed at $\mathrm{mRNA}$ and protein level. Expression of C3 was analysed at mRNA level.

2. Fully differentiated M2 macrophages were stimulated with IL-4 (20 ng/mL; R\&D Systems) for different time periods. Expression of C3aR was analysed at mRNA and protein level. Expression of C3 was analysed at mRNA level.

3. IL-4 activated M2a macrophages were stimulated with ST$1006(10 \mu \mathrm{M})$ for different time periods as indicated. Expression of $\mathrm{C} 3 \mathrm{aR}$ was analysed at protein level.

\section{Histamine Receptor Ligands}

The following histamine receptor ligands were used in this study: Histamine (or respective vehicle control; ALK-Abello, Madrid, Spain) as agonist for all HR; 2-pyridylethylamine (Tocris Bioscience, Bristol, UK) as selective H1R agonist; amthamine (Tocris Bioscience, Bristol, UK) as selective H2R agonist; ST-1006 (Institute of Pharmaceutical and Medicinal Chemistry, Heinrich Heine University, Duesseldorf, Germany) as H4R agonist [25]; JNJ39758979 (Sigma Aldrich, Deisenhofen, Germany) as selective H4R antagonist; Mercaptoethanol (Sigma Aldrich, Deisenhofen, Germany) as vehicle control. All histamine receptor ligands were used at a concentration of $10 \mu \mathrm{M}$. In extensive previous studies, we could show that the concentration of $10 \mu \mathrm{M}$ is optimal to demonstrate and reproduce robust H4R agonist mediated effects [26].

\section{Real-Time Quantitative LightCycler RT-PCR}

Total RNA was isolated using the RNeasy kit (Qiagen, Hilden, Germany) according to the manufacturer's instructions. The cDNA was synthesized by reverse transcription (QuantiTect reverse transcription kit, Qiagen, Germany). Real-time quantitative PCR was performed according to the MIQE guidelines with Quantitect ${ }^{\circledR}$ primer assays for C3aR (QT00090398), C3 (QT00089698), IL-6 (QT00083720), H1R (QT00199857), H2R (QT00210378), H3R (QT00210861), H4R (QT00032326) and rps 20 (ribosomal protein S20) (QT00079247) using SYBR ${ }^{\circledR}$ Green according to the manufacturer's instructions (Qiagen, Hilden, Germany) using the LightCycler 480 . The amount of the target mRNA relative to the amount of the reference gene, ribosomal protein S20 (rps 20), mRNA in the same sample was calculated using the comparative Ct method also known as the [delta] [delta] Ct method provided by the Software LC 480 (Roche Molecular Biochemicals). The Ct values of both the calibrator and the samples of interest are normalized to the appropriate endogenous reference gene rps 20 .

Fig. 1. Modulation of $H 1 R, H 2 R$ and the H4R mRNA expressions during the differentiation process of M2 macrophages. Regulation of CD68 and CD163 expressions by histamine or histamine receptor agonists during the differentiation process of M2 macrophages. a Primary human monocytes were obtained from PBMCs after $2 \mathrm{~h}$ adherence. Monocytes were differentiated into M2 macrophages with M-CSF $(10 \mathrm{ng} / \mathrm{mL})$ only or with histamine and different HR agonists $(10 \mu \mathrm{M})$. Expressions of CD68 and CD163 were measured after different time periods as indicated. The mRNA expressions of the (b) H1R, (c) H2R, and (d) H4R in monocytes obtained by adherence were measured at day 0 (day 0 ) and in fully differentiated M2 macrophages after a differentiation period of 10 days (day 10), analysed by quantitative PCR and calculated by the [delta] [delta] $\mathrm{Ct}$ method, the target/reference (Tgt/Ref) ratios are indicated. Ex-

C3aR Is Down-Regulated by Histamine and by IL-4

\section{Flow Cytometric Analysis of CD68 and CD163}

Monocyte-derived M2 macrophages after day 1, 3 and 7, nonstimulated macrophages and macrophages treated with histamine or different HR agonists targeting the H1R, H2R, or the H4R during the whole differentiation process were carefully scraped from the culture plates and seeded $\left(5 \times 10^{5}\right.$ cells per well) into 96 well plates. Fc receptors were blocked by incubation in a buffer containing 10 $\mu \mathrm{g} / \mathrm{mL}$ heat-aggravated human immunoglobulin G (IgG; Sigma, Deisenhofen, Germany). An extracellular epitope of CD163 was stained with anti-human CD163-PE (mouse monoclonal IgG1, 1 $\mu \mathrm{g} / 100 \mu \mathrm{L}$; BioLegend, San Diego, CA, USA), the respective isotype control IgG1 was tested in parallel. Cells were fixed, permeabilized using the BD Cytofix/Cytoperm fixation/permeabilization kit (BD Bioscience) and CD68, which is intracellularly expressed in cytoplasmic granules and was stained with anti-human CD68-APC (mouse monoclonal IgG2b, 0,125 $\mu \mathrm{g} / 100 \mu \mathrm{L}$; BioLegend); the respective isotype control IgG2b was tested in parallel. Sample acquisition was performed by flow cytometry (FACS Calibur, Becton Dickinson, Heidelberg, Germany) and mean fluorescence intensities (MFI) were calculated using the CellQuest Pro software (Becton Dickinson). To assess cell viability, macrophages were incubated with Annexin V-FITC and Propidium iodide for $15 \mathrm{~min}$ (BD Bioscience) and analysed by flow cytometry (FACS Calibur, Becton Dickinson).

\section{Flow Cytometric Analysis of C3aR}

Fully differentiated M2 macrophages and macrophages treated with histamine or ST-1006 during the whole differentiation process were carefully scraped from the culture plates and seeded $(5 \times$ $10^{5}$ cells per well) into 96 well plates. Fc receptors were blocked by incubation in a buffer containing $10 \mu \mathrm{g} / \mathrm{mL}$ heat-aggravated human IgG (Sigma, Deisenhofen, Germany). A specific epitope of C3aR was stained with anti-human C3aR-APC (mouse monoclonal IgG2b, $1 \mu \mathrm{g} / 100 \mu \mathrm{L}$; BioLegend, San Diego, CA, USA), the respective isotype control IgG2b was tested in parallel. Sample acquisition was performed by flow cytometry (FACS Calibur [Fig. 1, 2, 4b, 6e] or FACS Canto II [Fig. 4c-f] Becton Dickinson, Heidelberg, Germany) and MFI were calculated by CellQuest Pro or FACS Diva software (Becton Dickinson) respectively. To assess cell viability, macrophages were incubated with Annexin V-FITC and Propidium iodide for $15 \mathrm{~min}$ (BD Bioscience) and analysed by flow cytometry (FACS Calibur, Becton Dickinson).

The MFI values of the isotype controls of non-stimulated or of stimulated cells were in the same range. Histamine or specific his-

pressions of CD68 and CD163 were analysed by flow cytometry. e The expression of CD68 was measured at different days of the differentiation process as indicated on non-stimulated cells. Expressions of CD68 in (f) histamine, (g) 2-pyridylethylamine (H1R agonist), (h) amthamine (H2R agonist) and (i) in ST-1006 treated cells are shown (only non-stimulated samples with MFI $<450$ were included). $\mathbf{j}$ The expression of CD163 was measured at different days of the differentiation process as indicated on non-stimulated cells. Expressions of CD163 in (k) histamine, (I) 2-pyridylethylamine (H1R agonist), (m) amthamine (H2R agonist) and in (n) ST-1006 treated cells are shown. Significant differences, as determined by the Wilcoxon signed rank test are indicated as follows: ${ }^{*} p<0.05$; ${ }^{* *} p<$ 0.01 ; $^{* * *} p<0.001$; medians are shown in the graphs. ns, non-stimulated; Hist, histamine; MFI, mean fluorescence intensity.

(For figure 1 see next page.) 


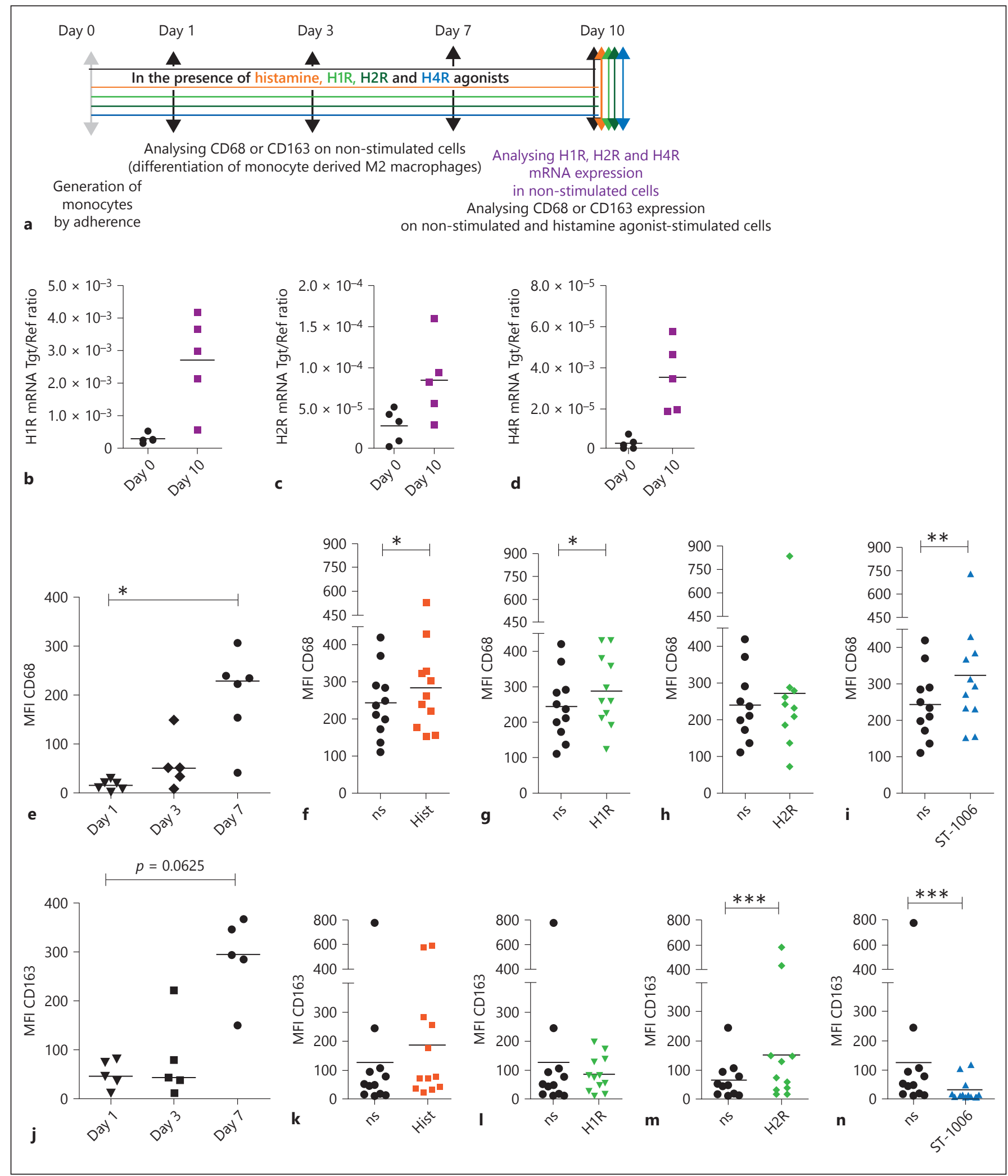


Fig. 2. The mRNA and surface expression levels of $\mathrm{C} 3 \mathrm{aR}$ are down-regulated in the presence of the H4R agonist ST-1006 during the differentiation process of M2 macrophages. a Primary human monocytes were differentiated into M2 macrophages (M-CSF, $10 \mathrm{ng} / \mathrm{mL}$ ) for 10 days in the presence of histamine $(10 \mu \mathrm{M})$ or ST-1006 $(10 \mu \mathrm{M})$ or left non-stimulated. b C3aR mRNA expression was analysed by quantitative PCR and calculated by the [delta] [delta] Ct method normalized to the nonstimulated samples. c C3aR surface expression was detected by flow cytometry. d Overlay of the histograms of one representative experiment out of the 7 is shown. Significant differences, as determined by the Wilcoxon signed rank test, are indicated as follows: ${ }^{*} p<0.05$; medians are shown in the graphs. ns, non-stimulated; Hist, histamine; MFI, mean fluorescence intensity.

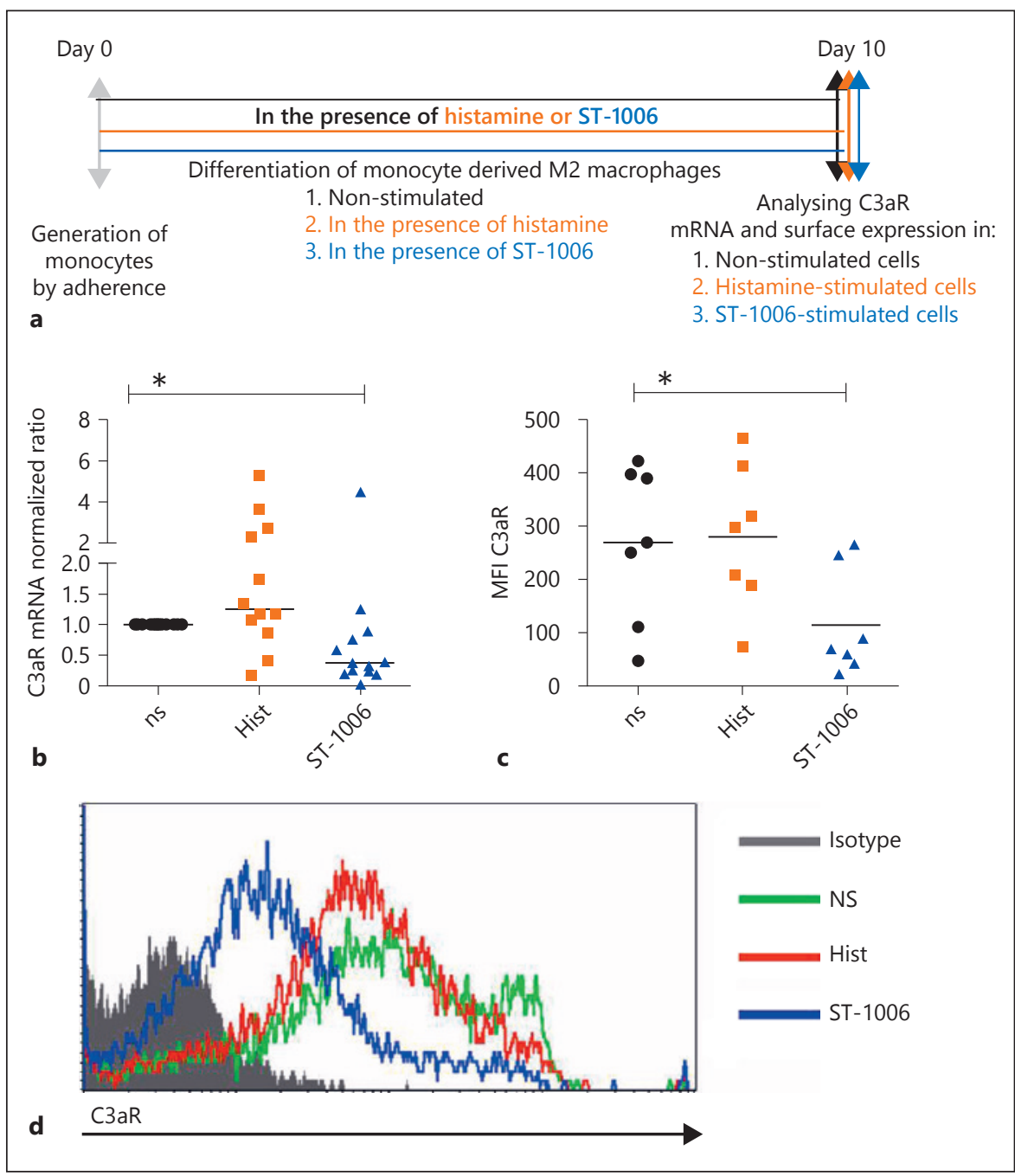

tamine receptor agonists did not influence the unspecific binding of immunoglobulins to $\mathrm{Fc}$ receptors. To analyse the specific expression levels of CD68, CD163 or C3aR we subtracted the MFI values of the isotypes from the respective MFI values of the specific staining.

\section{Statistics}

For statistical analyses, the software GraphPad Prism Version 5.0 was used (GraphPad software, San Diego, CA, USA). Wilcoxon matched pairs test or Repeated Measures by ANOVA, Dunnett's Multiple Comparison test was performed and the median or mean is shown in the graph. A $p$ value $<0.05$ was regarded as statistically significant $(p<0.05$ was labelled with $* p<0.01$ was labelled with ${ }^{* *} p<0.001$ was labelled with $\left.* * *\right)$.

Ethics

The investigation of the role of the HR in inflammatory diseases was approved by the local Ethics Committee of the Hannover Medical School (Vote 4253) and was conducted according to the Declaration of Helsinki Principles.

C3aR Is Down-Regulated by Histamine and by IL- 4

\section{Results}

The H1R, H2R and the H4R mRNA Expressions Are Induced or Up-Regulated by Trend during the Differentiation Process of M2 Macrophages. The Expression Levels of the Macrophage Differentiation Marker CD68 and the Scavenger Receptor CD163 Are Differentially Regulated in the Presence of Histamine or Histamine Receptor Agonists during the Differentiation Process of M2 Macrophages

In vitro differentiation of monocytes (day 0 ) in the presence of M-CSF led to the generation of M2 macrophages (day 10) by up-regulating or inducing the expression of the H1R, H2R and the H4R mRNA by trend (Fig. 1b-d). The differentiation marker CD68 and the characteristic M2 macrophage marker CD163 were upregulated during the differentiation process and ex- 

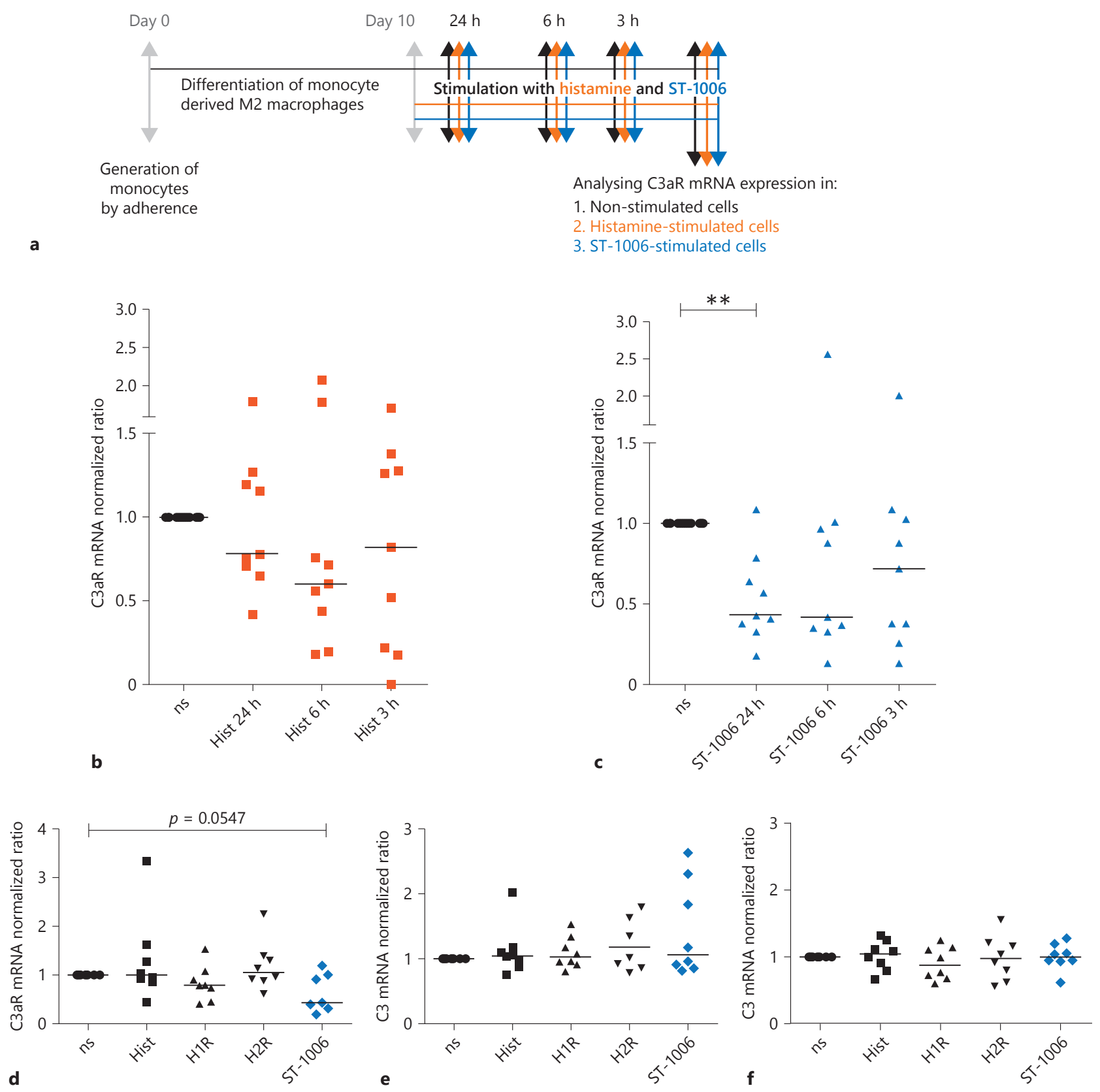

Fig. 3. C3aR mRNA expression is down-regulated upon stimulation with the H4R agonist ST-1006 after $24 \mathrm{~h}$ and by trend with histamine after $6 \mathrm{~h}$ in fully differentiated M2 macrophages. a Primary human monocytes were differentiated into M2 macrophages (M-CSF, $10 \mathrm{ng} / \mathrm{mL}$ ) for 10 days. Fully differentiated M2 macrophages were stimulated for different time periods as indicated with histamine or ST-1006. b Expression of C3aR mRNA in fully differentiated M2 macrophages stimulated for different time periods as indicated with histamine. c Expression of C3aR mRNA in fully differentiated M2 macrophages stimulated for different time periods as indicated with ST-1006. d Expression of C3aR mRNA in fully differentiated M2 macrophages stimulated with histamine,
$\mathrm{H} 1 \mathrm{R}$ agonist 2-pyridylethylamine, $\mathrm{H} 2 \mathrm{R}$ agonist amthamine and with ST-1006 for $24 \mathrm{~h}$. Expression of C3 mRNA in fully differentiated M2 macrophages stimulated with histamine, the H1R agonist 2-pyridylethylamine, the $\mathrm{H} 2 \mathrm{R}$ agonist amthamine and with ST-1006 (e) for $6 \mathrm{~h}$ and (f) for $24 \mathrm{~h}$. For all HR agonists a concentration of $10 \mu \mathrm{M}$ was used. $\mathrm{C} 3 \mathrm{aR}$ or $\mathrm{C} 3 \mathrm{mRNA}$ expressions was analysed by quantitative PCR and calculated by the [delta] [delta] Ct method and normalized to the non-stimulated samples. Significant differences, as determined by the Wilcoxon signed rank test are indicated as follows: ${ }^{* *} p<0.01$; medians are shown in the graphs. ns, non-stimulated; Hist, histamine. 


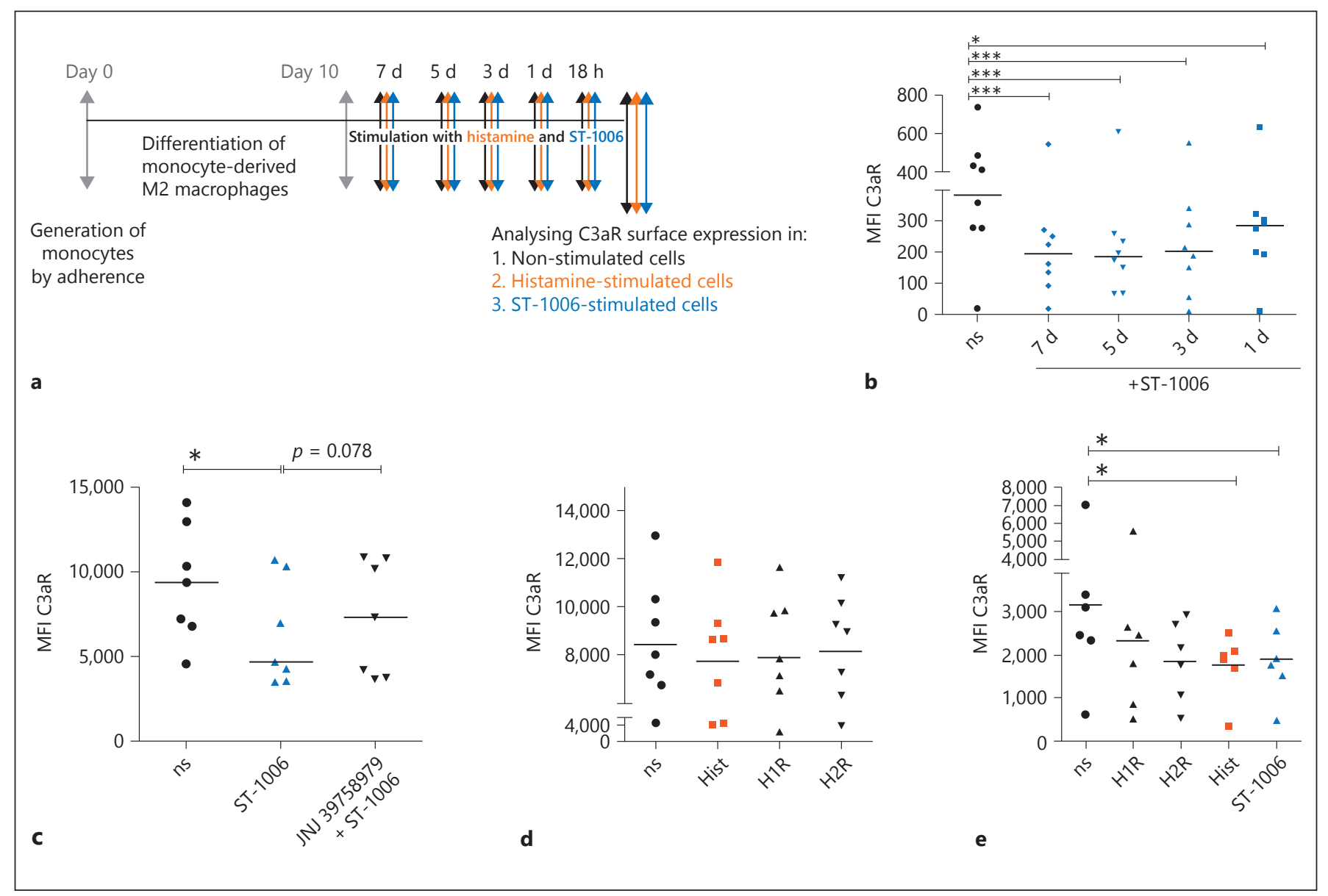

Fig. 4. The H4R agonist ST-1006 selectively down-regulates the surface expression of C3aR on fully differentiated human M2 macrophages over time. a Primary human monocytes were differentiated into M2 macrophages (M-CSF, $10 \mathrm{ng} / \mathrm{mL}$ ) for 10 days. The M2 macrophages were plated out in 5 wells and stimulated for different time periods with ST-1006. One well was left without treatment, one was immediately stimulated with ST-1006 (7 d), the next well was stimulated with ST-1006 2 days later ( $5 \mathrm{~d}$ ) and so on 2 days later ( $3 \mathrm{~d}$ ) and 2 days later ( $1 \mathrm{~d}$ ) without changing the medium. After 7 days cells were collected from all wells for flow cytometric $\mathrm{C} 3 \mathrm{aR}$ analysis at the same time point. b Fully differentiated M2 macrophages were stimulated for different time periods as indicated with ST-1006 $(10 \mu \mathrm{M})$ (medians are shown in the graphs). c Pre-incubation with the specific H4R antagonist JNJ 39758979 30 min before stimulation with ST-1006 for 3 days partly reversed the down-regulation of C3aR expression (medians are shown in

pressed at high levels at day 7 when compared to the expression levels at day 1 or day 3 of the differentiation process (Fig. 1e, j). We differentiated monocytes to M2 macrophages with M-CSF and in the presence of M-CSF supplemented with histamine, 2-pyridylethylamine (H1R agonist), amthamine (H2R agonist) and with ST- the graph). d Fully differentiated M2 macrophages were stimulated with histamine, the H1R agonist 2-pyridylethylamine and the H2R agonist amthamine for 3 days (means are shown in the graph). e Fully differentiated M2 macrophages were stimulated with histamine the H1R agonist 2-pyridylethylamine, the H2R agonist amthamine or ST-1006 for $16-18 \mathrm{~h}$ (means are shown in the graph). $\mathbf{f}$ One experiment out of 6 from graph (e) is shown. M2 macrophages were identified as CD163 positive cells. The histograms show the surface expression of C3aR on CD163 positive non-stimulated, histamine or ST-1006-treated M2 macrophages. For all HR agonists a concentration of $10 \mu \mathrm{M}$ was used. Significant differences, as determined by the Wilcoxon signed rank test or the Repeated Measures by ANOVA, Dunnett's Multiple Comparison test (b), are indicated as follows: ${ }^{*} p<0.05$; ${ }^{* * *} p<0.001$; ns, nonstimulated; Hist, histamine; d, day; MFI, mean fluorescence intensity.

(For figure 4 see next page.)
1006. Expression levels of CD68 and CD163 were measured by flow cytometry. We observed that the expression of CD68 was up-regulated on fully differentiated M2 macrophages treated by histamine, 2-pyridylethylamine and ST-1006. Amthamine did not regulate CD68 expression (Fig. 1f-i). In contrast, the expression of 


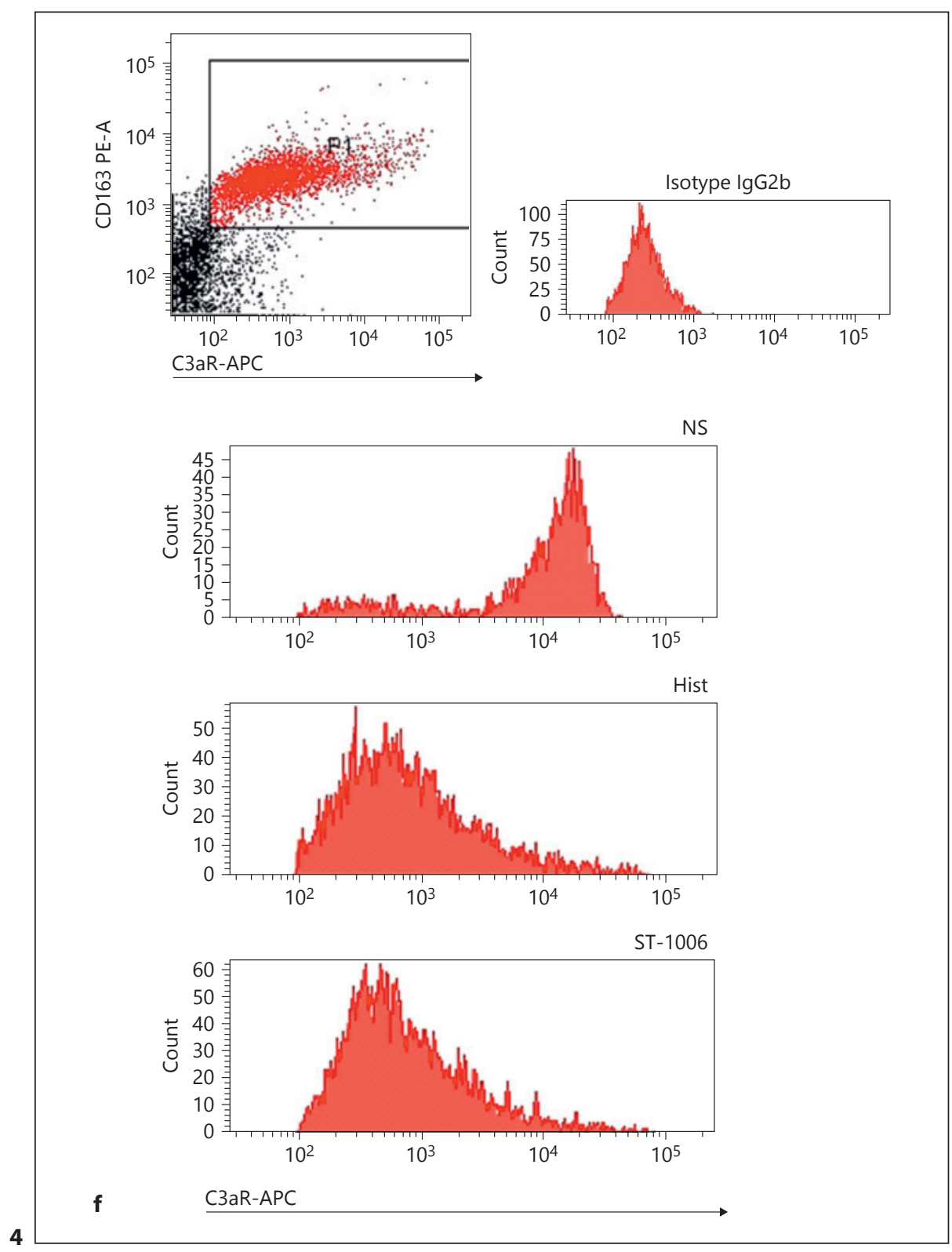

CD163 was significantly up-regulated by amthamine stimulation. Stimulation via $\mathrm{H} 4 \mathrm{R}$ down-regulated CD163 expression. Histamine and the H1R agonist 2-pyridylethylamine had no effect on CD163 expression (Fig. $1 \mathrm{k}-\mathrm{n}$ ).

The cell viability of M2 macrophages showed no remarkable deviations between cells treated with histamine (data not shown) or ST-1006 during the period of differentiation as assessed by Propidium Iodide and Annexin V-FITC staining when compared to un-treated cells (online suppl. Fig. 1, see www.karger.com/ doi/10.1159/000490426).
The mRNA and Surface Expression Levels of C3aR Are Down-Regulated in the Presence of the H4R Agonist ST-1006 during the Differentiation Process of M2 Macrophages

We examined the influence of histamine, in particular via $\mathrm{H} 4 \mathrm{R}$, on $\mathrm{C} 3 \mathrm{aR}$ expression levels during the differentiation process from monocytes to macrophages. We differentiated monocytes to M2 macrophages: (i) with M-CSF, (ii) with M-CSF and in the presence of histamine, (iii) with M-CSF and in the presence of ST-1006. Expression levels of C3aR were measured by quantitative PCR and by flow cytometry. 


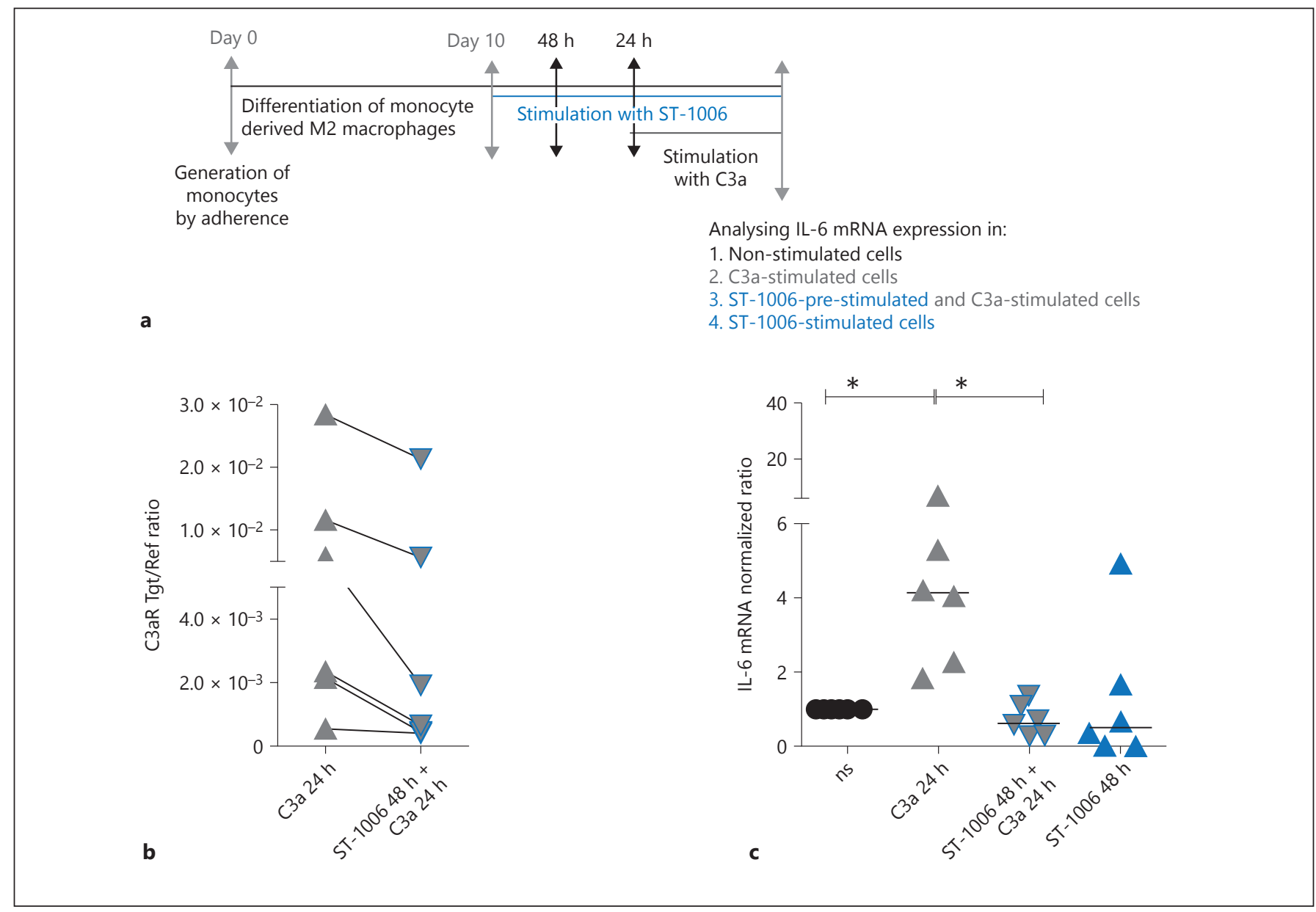

Fig. 5. The down-regulation of $\mathrm{C} 3 \mathrm{aR}$ via $\mathrm{H} 4 \mathrm{R}$ is of functional relevance. ST-1006-treated M2 macrophages express lower levels of C3aR mRNA. Stimulation with C3a results in lower amounts of IL-6 mRNA expression in ST-1006-treated when compared to untreated cells. a Primary human monocytes were differentiated into M2 macrophages (M-CSF, $10 \mathrm{ng} / \mathrm{mL}$ ) for 10 days. Fully differentiated M2 macrophages were stimulated with ST-1006 (10 $\mu \mathrm{M})$ for $48 \mathrm{~h}$. After $24 \mathrm{~h}$ the cells were stimulated with C3a. b The C3aR mRNA expression was down-regulated by ST-1006. These samples were included in the further analysis. c After a time period of

We observed that the mRNA and surface expressions of $\mathrm{C} 3 \mathrm{aR}$ were significantly down-regulated of $62 \%$ and of $74 \%$, respectively, on macrophages treated with M-CSF and ST-1006 during the differentiation period when compared to macrophages supplemented with M-CSF only (Fig. 2b-d). Histamine had no consistent effects at the expression levels of C3aR when the substance is presented during the whole differentiation process. This may be due to the long incubation period of histamine or due to opposite effects at other HR.

C3aR Is Down-Regulated by Histamine and by IL-4
24 h, ST-1006- and un-treated cells were stimulated with C3a for $24 \mathrm{~h}$. Another part was stimulated with ST-1006 only for $48 \mathrm{~h}$ to show that ST-1006 alone has no effect at IL-6 mRNA expression. C3aR and IL- 6 mRNA expressions were detected by quantitative PCR and calculated by the [delta] [delta] Ct method. For C3aR mRNA expression, the target/reference (Tgt/Ref) ratio is depicted. For IL-6 mRNA expression values were normalized to the nonstimulated samples. Significant differences, as determined by the Wilcoxon signed rank test are indicated as follows: ${ }^{*} p<0.05$; medians are shown in the graphs. NS, non-stimulated.

\section{C3aR mRNA Expression is Down-Regulated upon Stimulation with the H4R Agonist ST-1006 after $24 \mathrm{~h}$ and by Trend with Histamine after $6 \mathrm{~h}$ in Fully Differentiated M2 Macrophages}

Next, we studied the influence of histamine or ST-1006 on fully differentiated human M2 macrophages. Fully differentiated human M2 macrophages were stimulated with histamine or ST-1006 for different periods of time. $\mathrm{C} 3 \mathrm{aR}$ expression was analysed by quantitative PCR. We observed down-regulation of C3aR mRNA expression upon histamine stimulation after $6 \mathrm{~h}$ by trend and a time- 
Fig. 6. IL-4 down-regulates C3aR mRNA and surface expressions on fully differentiated M2 macrophages. The H4R agonist ST-1006 potentiated the IL-4-induced effect. a Primary human monocytes were differentiated into M2 macrophages (M-CSF, $10 \mathrm{ng} / \mathrm{mL}$ ) for 10 days. Fully differentiated M2 macrophages were stimulated for different time periods as indicated with IL-4 (20 ng/mL). b, c C3aR mRNA expression was detected by quantitative PCR and calculated by the [delta] [delta] Ct method and normalized to the non-stimulated samples. d Primary human monocytes were differentiated into M2 macrophages (M-CSF, $10 \mathrm{ng} / \mathrm{mL}$ ) for 10 days and activated by IL-4 ( $20 \mathrm{ng} / \mathrm{mL})$ for $48 \mathrm{~h}$. IL- $4 \mathrm{ac}$ tivated M2a macrophages were stimulated for different time periods as indicated with ST-1006. e The cells were all collected at the same time point to analyse $\mathrm{C} 3 \mathrm{aR}$ surface expression by flow cytometry. Significant differences, as determined by the Wilcoxon signed rank test, are indicated as follows: ${ }^{*} p<0.05$; ${ }^{* *} p<0.01$; medians are shown in the graphs. ns, non-stimulated; d, day; MFI, mean fluorescence intensity.

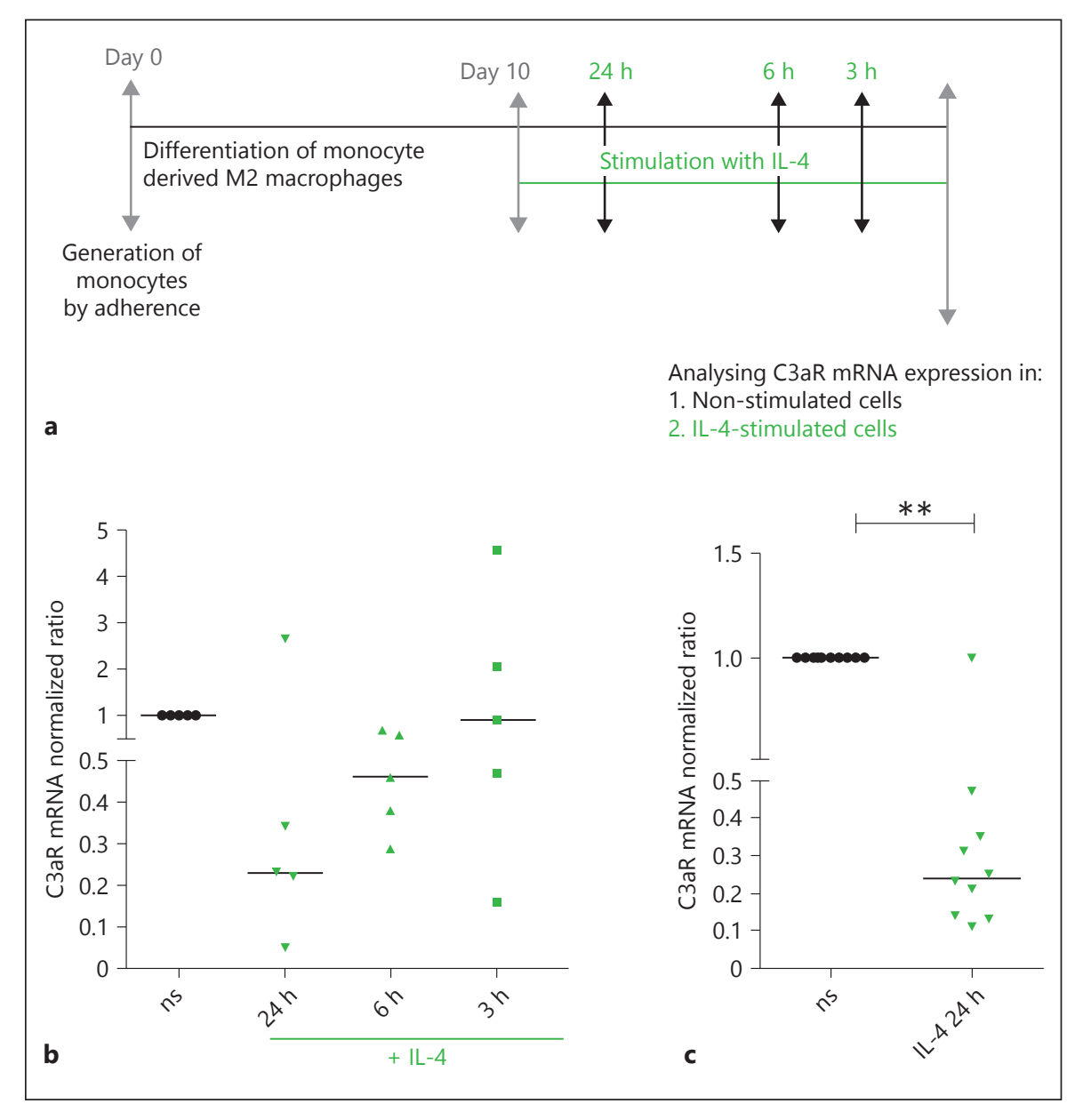

(For figure 6d, e see next page.) dependent down-regulation of C3aR mRNA expression upon stimulation with ST- 1006 of $57 \%$ after $24 \mathrm{~h}$ (Fig. 3b, c). Stimulation with 2-pyridylethylamine (H1R agonist) or amthamine (H2R agonist) for $24 \mathrm{~h}$ did not regulate C3aR mRNA expression levels when compared to untreated samples (Fig. 3d).

C3 mRNA expression levels were not regulated by histamine, 2-pyridylethylamine (H1R agonist), amthamine (H2R agonist) or ST-1006 (H4R agonist) after a stimulation period of $6 \mathrm{~h}$ or $24 \mathrm{~h}$ (Fig. 3e, f).

Histamine or the H4R Agonist ST-1006 Differentially

Down-Regulates the C3aR Surface Expression on Fully

Differentiated M2 Macrophages

Fully differentiated M2 macrophages were stimulated for different time periods with histamine or ST-1006. Analysing the expression of C3aR by flow cytometry on M2 macrophages, we detected a significant down-regulation of C3aR surface expression by ST- 1006 over time, which was most pronounced after 3, 5 and 7 days (Fig. $4 \mathrm{~b}$ ), whereas histamine had less effects at these late time points (data not shown). To rule out if this effect is specific for the H4R, we blocked the receptor $30 \mathrm{~min}$ before stimulation. For blocking the H4R we used the H4R antagonist JNJ 39758979, which has been shown to be effective in reducing histamine-induced pruritus in a clinical study in healthy subjects [27]. As shown in Figure 4c, in the presence of the selective H4R antagonist JNJ 39758979, the down-regulation of C3aR surface expression was partly reversed, confirming a functional role of the H4R for this effect.

To investigate if the down-regulation of $\mathrm{C} 3 \mathrm{aR}$ is regulated also by other HR, we stimulated the M2 macrophages besides ST-1006 with histamine, 2-pyridylethylamine (H1R agonist) and with amthamine (H2R agonist) for 3 days. As shown in Figure 4d, we revealed a slight downregulation of $\mathrm{C} 3 \mathrm{aR}$ by trend with histamine. We assumed that different time kinetics in the histamine- or histamine receptor-specific agonist-mediated pathways exist. Therefore, we stimulated M2 macrophages with histamine, 2-pyridylethylamine (H1R agonist), amthamine (H2R ag- 


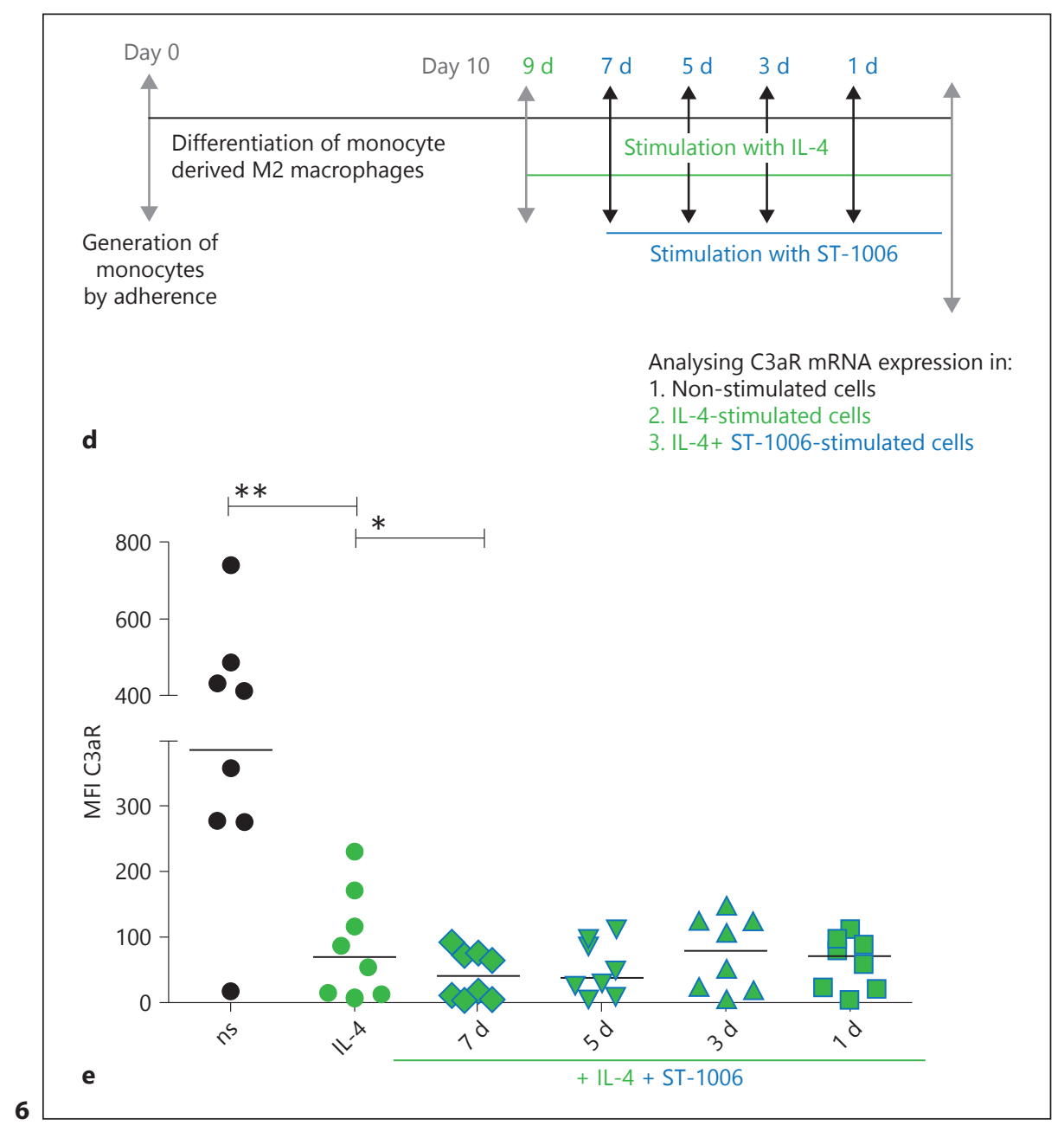

onist) or with ST-1006, instead of 3 days, for a shorter time period of 16-18 h. Analysing C3aR surface expression, we observed that ST-1006 as well as histamine down-regulated C3aR expression after 16-18 h when compared to nonstimulated samples (Fig. 4e). The H1R and H2R agonists were less effective.

The Down-Regulation of C3aR via H4R Is of Functional Relevance. ST-1006-Treated M2 Macrophages Express Lower Levels of C3aR mRNA. Stimulation with C3a Results in Lower Amounts of IL-6 mRNA Expression in ST-1006-Treated when Compared to Un-Treated Cells

Fully differentiated human M2 macrophages were treated with ST-1006 for $24 \mathrm{~h}$ or were left un-treated. The cells in the ST-1006-treated group showed a down-regulation of C3aR mRNA expression (Fig. 5b). After $24 \mathrm{~h}$, both groups were stimulated with $\mathrm{C} 3 \mathrm{a}(1 \mathrm{ng} / \mathrm{mL})$ for further $24 \mathrm{~h}$. M2 macrophages, which were stimulated with $\mathrm{C} 3 \mathrm{a}$, only showed a more than 4 fold up-regulation of
IL-6 mRNA expression when compared to the cells where the C3aR had been down-regulated by ST-1006 before. Stimulation of the cells with ST-1006 only for $24 \mathrm{~h}$ had no effect at the IL-6 mRNA expression (Fig. 5c).

\section{IL-4 Down-Regulates C3aR mRNA and Surface Expressions on Fully Differentiated Human M2 Macrophages}

Fully differentiated human M2 macrophages were stimulated with IL-4 $(20 \mathrm{ng} / \mathrm{mL})$ for different time periods. C3aR expression was analysed by RT-PCR. We observed a stepwise down-regulation of C3aR mRNA expression by time (Fig. 6b). We performed some additional experiments using the optimal time period of $24 \mathrm{~h}$ for IL-4 stimulation and found that C3aR mRNA was significantly down-regulated of 75\% (Fig. 6c). The expression of C3aR on the cell surface was analysed by flow cytometry. Here, we observed a significant down-regulation of C3aR expression by IL- 4 after $48 \mathrm{~h}$ (data not 


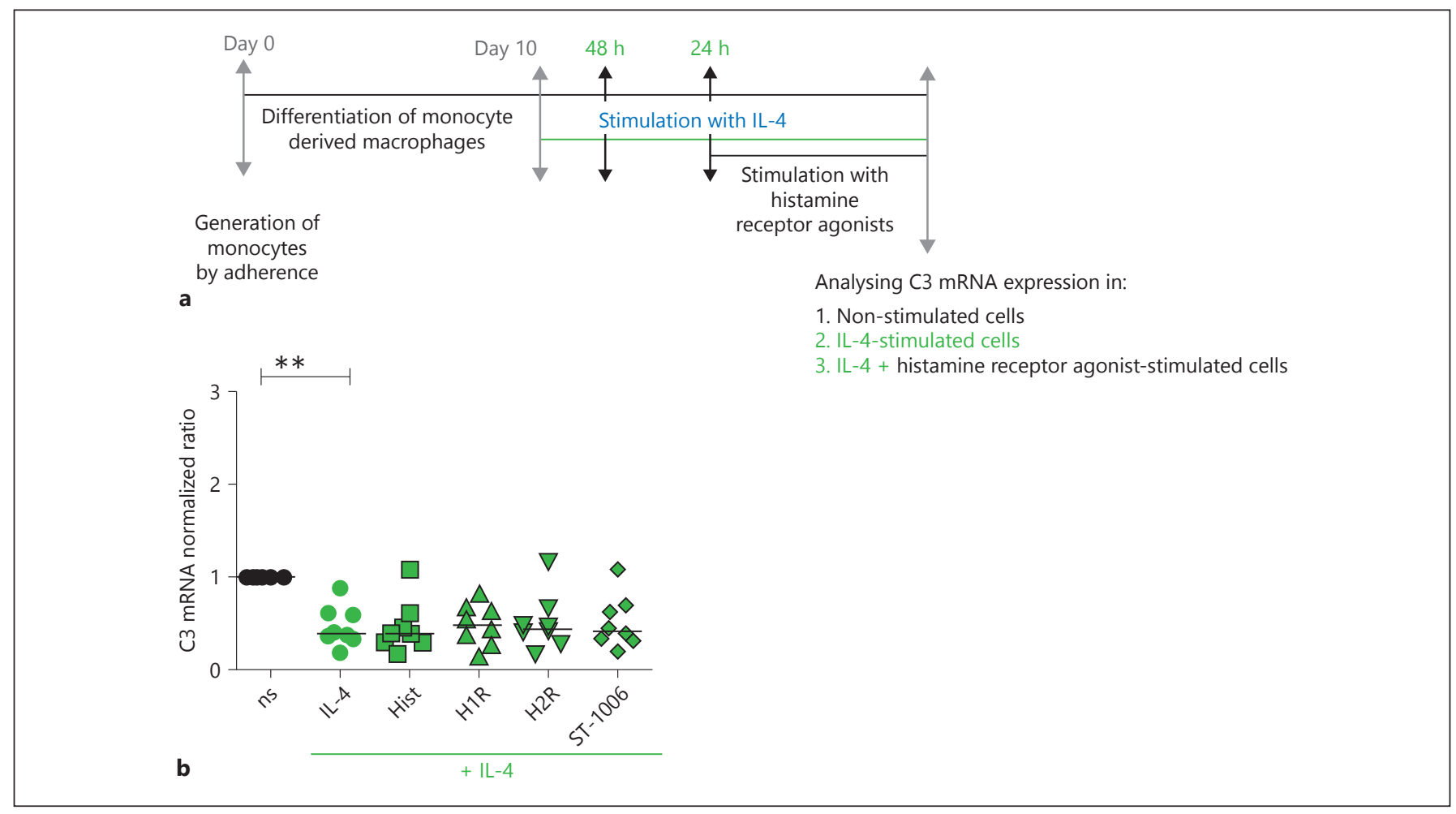

Fig. 7. IL-4 down-regulates C3 mRNA expression. Histamine or histamine receptor-specific agonists do not regulate C3 mRNA expression in IL-4-activated M2a macrophages. a Primary human monocytes were differentiated into M2 macrophages (M-CSF, 10 $\mathrm{ng} / \mathrm{mL}$ ) for 10 days. Fully differentiated M2 macrophages were stimulated with IL-4 $(20 \mathrm{ng} / \mathrm{mL})$ for $24 \mathrm{~h}$ and then stimulated with histamine, H1R agonist 2-pyridylethylamine, H2R agonist

shown). IL-4 activated M2a macrophages were stimulated with ST-1006 for different time periods. C3aR expression was analysed by flow cytometry. Interestingly we could show that stimulation of activated M2a macrophages with ST-1006 potentiated the strong down-regulation of C3aR surface expression by IL-4 at day 7 (Fig. 6e).

Importantly, C3 mRNA expression was also significantly down-regulated upon stimulation with IL-4. Stimulation of IL- 4 activated M2a macrophages with different histamine receptor agonists showed no further effect on C3 mRNA expression (Fig. 7b).

\section{Discussion}

Alternatively activated M2 macrophages are considered as counterparts of classically activated M1 macrophages by playing a crucial role in tissue development, sustaining the homeostasis and mediating wound repair following dam- amthamine and with ST-1006 for further $24 \mathrm{~h}$. For all HR agonists a concentration of $10 \mu \mathrm{M}$ was used. b C 3 mRNA expression was analysed by quantitative PCR and calculated by the [delta] [delta] $\mathrm{Ct}$ method and normalized to the non-stimulated samples. Significant differences, as determined by the Wilcoxon signed rank test, are indicated as follows: ${ }^{* *} p<0.01$; medians are shown in the graphs. ns, non-stimulated; Hist, histamine.

age. The M2 macrophage phenotype is further divided into different subgroups depending on the cytokine and chemokine milieu in the microenvironment of the tissue or the stimuli used to generate M2 macrophages in vitro [2, $3,28]$. In the acute phase of AD secretion of IL- 4 and IL-13 from Th2 cells, eosinophils or basophils provide a microenvironment favouring $\mathrm{M} 2 \mathrm{a}$ macrophage polarization [29]. We generated human monocyte derived M2 macrophages to investigate the expression levels of HR and expression levels of macrophage differentiation marker CD68 and CD163. We detected that the H1R, H2R and $\mathrm{H} 4 \mathrm{R}$ were induced or up-regulated by trend during the differentiation process of M2 macrophages. CD68 and CD163 were up-regulated during the differentiation process. CD68 and CD163 expression levels were differentially regulated when histamine, H1R, H2R or H4R agonists were presented to the cells during the differentiation process. Remarkably, CD163 was up-regulated via H2R but downregulated via H4R. Therefore, it was not surprising that 
histamine targeting all 3 receptors showed no consistent effect on CD163 expression levels.

Our aim was to investigate $\mathrm{C} 3 \mathrm{aR}$ expression on $\mathrm{M} 2$ macrophages in response to mediators present in allergic situations like IL- 4 or histamine.

To link the complement system with histaminergic pathways, we differentiated monocytes to fully differentiated M2 macrophages in vitro in the presence of M-CSF and in addition in the presence of histamine or the H4R agonist ST-1006. The C3aR expression was measured at the end of the differentiation process at mRNA level and by flow cytometry. We detected a significant down-regulation of C3aR expression at mRNA level as well as on the cell surface in monocyte derived macrophages differentiated in the presence of M-CSF and ST-1006 when compared to cells differentiated in the presence of M-CSF only.

Moreover, the stimulation of fully differentiated M2 macrophages with histamine or ST-1006 for different periods of time resulted in a time-dependent down-regulation of C3aR expression at mRNA level and on the cell surface. Of note, histamine down-regulated C3aR expression at earlier time points when compared with the effects of ST-1006.

To prove if these effects are specific for the H4R, we stimulated fully differentiated M2 macrophages with specific agonists for H1R and H2R. Targeting the H1R or $\mathrm{H} 2 \mathrm{R}$ did not modulate C3aR mRNA or surface expression. The down-regulation of $\mathrm{C} 3 \mathrm{aR}$ via $\mathrm{H} 4 \mathrm{R}$ is of functional relevance, since the C3a-induced IL-6 mRNA expression was diminished in ST-1006-treated cells when compared to un-treated cells.

We observed that the C3aR expression was down-regulated by IL-4 in a time dependent manner, which was significant at mRNA level as well as for cell surface expression. In line with our results a previously published study showed a down-regulation of the C3aR expression on human monocytes and monocyte derived DCs by IL- 4 which was accompanied by an inhibition of in vivo mobilization of respective cells in response to C3a [15]. These data corroborate our findings and point to a regulatory role of Th2 cytokines to influence C3a-mediated downstream signaling by reducing C3aR expression levels on monocytes, DCs and on M2 macrophages. A potential crosstalk of Th2 cytokines with the $\mathrm{C} 3 \mathrm{a} / \mathrm{C} 3 \mathrm{aR}$ axis is further supported by observations that vice versa C3a down-regulated the Th2 response to epicutaneously applied ovalbumin in a mouse model of $\mathrm{AD}$ when comparing $\mathrm{C} 3 \mathrm{aR}$ knock out to wildtype mice [30]. Furthermore, a role of $\mathrm{C} 3 / \mathrm{C} 3 \mathrm{aR}$ axis in the protection of Th2-induced allergic contact dermatitis was described in a mouse model of allergic skin inflammation also when comparing C3aR knock out to wildtype mice [31]. As opposed to the findings in Th2-dominated situations, former studies identified the Th1-related inflammatory Type I interferons as potent inducers of C3aR expression on human T lymphocytes [18], whereas Type I and Type II interferons strongly up-regulate the C3aR expression on human monocyte derived DCs [16] and on keratinocytes [14].

In inflammatory conditions, the complement system actively regulates various steps of an inflammatory response by triggering degranulation of mast cells, chemotaxis and activation of leukocytes $[11,13]$. However, the functional role of the $\mathrm{C} 3 / \mathrm{C} 3 \mathrm{aR}$ axis in allergic situations has not yet been sufficiently studied. With our study, we provide first evidence that in Th2-dominated local microenvironments, where histamine is present in high concentrations, the $\mathrm{C} 3 \mathrm{aR}$ is down-regulated on human M2 macrophages. This is induced by IL-4 and histamine via the H4R.

The reduced expression of C3aR in response to IL- 4 or histamine via the H4R may influence the state of complement activation by reducing the sensitivity to C3a-induced down-stream signaling as shown for IL-6 in this study and thereby tipping the balance between inflammatory and homeostatic situations. These data may be relevant in the assessment of H4R antagonists in clinical trials for $\mathrm{AD}$ and other inflammatory skin diseases such as psoriasis [32].

\section{Disclosure Statement}

The authors declare that they have no conflicts of interest to disclose.

\section{Funding Source}

This study was supported by grants from the Deutsche Forschungsgemeinschaft DFG: Gu434/6-1. Funding for this research was provided by Janssen Research and Development, LLC.

\section{Author Contributions}

S.M. is the primary author who conducted data collection, study design and analysis, interpretation of the data and writing the first draft of the manuscript. D.A. performed most of the experiments, generating and stimulating the macrophages performing ELISA and quantitative PCR. L.R. performed a part of these experiments. H.S. provided the H4R-agonist ST-1006 and made contributions to the conception, design and interpretation of the data. R.G. made significant contributions to the conception and design of the study. T.W. made substantial contributions to the conception, design of the study and interpretation of the data. All authors reviewed, revised and approved of the manuscript for publication. 


\section{References}

1 Stout RD, Jiang C, Matta B, Tietzel I, Watkins SK, Suttles J: Macrophages sequentially change their functional phenotype in response to changes in microenvironmental influences. J Immunol 2005;175:342-349.

2 Hume DA: Differentiation and heterogeneity in the mononuclear phagocyte system. Mucosal Immunol 2008;1:432-441.

3 Mosser DM, Edwards JP: Exploring the full spectrum of macrophage activation. Nat Rev Immunol 2008;8:958-969.

4 Werfel T: The role of leukocytes, keratinocytes, and allergen-specific IgE in the development of atopic dermatitis. J Invest Dermatol 2009;129:1878-1891.

5 Werfel T, Allam JP, Biedermann T, Eyerich K, Gilles S, Guttman-Yassky E, et al: Cellular and molecular immunologic mechanisms in patients with atopic dermatitis. J Allergy Clin Immunol 2016;138:336-349.

6 Sica A, Mantovani A: Macrophage plasticity and polarization: In vivo veritas. J Clin Invest 2012;122:787-795.

7 Schultze JL, Schmieder A, Goerdt S: Macrophage activation in human diseases. Semin Immunol 2015;27:249-256.

8 Ring J, Senter T, Cornell RC, Arroyave CM, Tan EM: Plasma complement and histamine changes in atopic dermatitis. Br J Dermatol 1979;100:521-530.

9 Lepow IH, Willms-Kretschmer K, Patrick RA, Rosen FS: Gross and ultrastructural observations on lesions produced by intradermal injection of human C3a in man. Am J Pathol 1970;61:13-23.

10 Hartmann K, Henz BM, Kruger-Krasagakes S, Kohl J, Burger R, Guhl S, et al: C3a and C5a stimulate chemotaxis of human mast cells. Blood 1997;89:2863-2870.

11 Schulman ES, Post TJ, Henson PM, Giclas PC: Differential effects of the complement peptides, C5a and C5a des arg on human basophil and lung mast cell histamine release. J Clin Invest 1988;81:918-923.

12 el-Lati SG, Dahinden CA, Church MK: Complement peptides C3a- and C5a-induced mediator release from dissociated human skin mast cells. J Invest Dermatol 1994;102:803806.
13 Kemper C, Kohl J: Novel roles for complement receptors in $\mathrm{T}$ cell regulation and beyond. Mol Immunol 2013;56:181-190.

14 Purwar R, Wittmann M, Zwirner J, Oppermann M, Kracht M, Dittrich-Breiholz O, et al: Induction of $\mathrm{C} 3$ and CCL2 by C3a in keratinocytes: A novel autocrine amplification loop of inflammatory skin reactions. J Immunol 2006;177:4444-4450.

15 Soruri A, Kiafard Z, Dettmer C, Riggert J, Kohl J, Zwirner J: IL-4 down-regulates anaphylatoxin receptors in monocytes and dendritic cells and impairs anaphylatoxin-induced migration in vivo. J Immunol 2003; 170:3306-3314.

16 Gutzmer R, Lisewski M, Zwirner J, Mommert S, Diesel C, Wittmann M, et al: Human monocyte-derived dendritic cells are chemoattracted to C3a after up-regulation of the $\mathrm{C} 3 \mathrm{a}$ receptor with interferons. Immunology 2004; 111:435-443.

17 Gutzmer R, Kother B, Zwirner J, Dijkstra D, Purwar R, Wittmann M, et al: Human plasmacytoid dendritic cells express receptors for anaphylatoxins $\mathrm{C} 3 \mathrm{a}$ and $\mathrm{C} 5 \mathrm{a}$ and are chemoattracted to C3a and C5a. J Invest Dermatol 2006;126:2422-2429.

18 Werfel T, Kirchhoff K, Wittmann M, Begemann G, Kapp A, Heidenreich F, et al: Activated human $\mathrm{T}$ lymphocytes express a functional C3a receptor. J Immunol 2000;165: 6599-6605.

19 Stander S, Steinhoff M: Pathophysiology of pruritus in atopic dermatitis: an overview. Exp Dermatol 2002;11:12-24.

20 Mommert S, Gschwandtner M, Gutzmer R, Werfel T: The role of the histamine $\mathrm{H} 4$ receptor in atopic dermatitis. Curr Allergy Asthma Rep 2011;11:21-28.

21 Gutzmer R, Gschwandtner M, Rossbach K, Mommert S, Werfel T, Kietzmann M, et al: Pathogenetic and therapeutic implications of the histamine $\mathrm{H} 4$ receptor in inflammatory skin diseases and pruritus. Front Biosci (Schol Ed) 2011;3:985-994.

22 Panula P, Chazot PL, Cowart M, Gutzmer R, Leurs R, Liu WL, et al: International union fbasic and clinical pharmacology. XCVIII. histamine receptors. Pharmacol Rev 2015;67:601-655.
23 Mamane Y, Chung Chan C, Lavallee G, Morin N, Xu LJ, Huang J, et al: The C3a anaphylatoxin receptor is a key mediator of insulin resistance and functions by modulating adipose tissue macrophage infiltration and activation. Diabetes 2009;58:2006-2017.

24 Capelo R, Lehmann C, Ahmad K, Snodgrass R, Diehl O, Ringleb J, et al: Cellular analysis of the histamine $\mathrm{H} 4$ receptor in human myeloid cells. Biochem Pharmacol 2016;103:74-84.

25 Sander K, Kottke T, Tanrikulu Y, Proschak E, Weizel L, Schneider EH, et al: 2,4-diaminopyrimidines as histamine $\mathrm{H} 4$ receptor ligands - scaffold optimization and pharmacological characterization. Bioorg Med Chem 2009;17:7186-7196.

26 Gschwandtner M, Koether B, Werfel T, Stark $\mathrm{H}$, Gutzmer R: Profiling of histamine H4 receptor agonists in native human monocytes. Br J Pharmacol 2013;170:136-143.

27 Kollmeier A, Francke K, Chen B, Dunford PJ, Greenspan AJ, Xia Y, et al: The histamine $\mathrm{H}_{4}$ receptor antagonist, JNJ 39758979, is effective in reducing histamine-induced pruritus in a randomized clinical study in healthy subjects. J Pharmacol Exp Ther 2014;350:181-187.

28 Mosser DM: The many faces of macrophage activation. J Leukoc Biol 2003;73:209-212.

29 Kasraie S, Werfel T: Role of macrophages in the pathogenesis of atopic dermatitis. Mediators Inflamm 2013;2013:942375.

30 Kawamoto S, Yalcindag A, Laouini D, Brodeur S, Bryce P, Lu B, et al: The anaphylatoxin C3a downregulates the Th2 response to epicutaneously introduced antigen. J Clin Invest 2004;114:399-407.

31 Niebuhr M, Baumer W, Kietzmann M, Wichmann K, Heratizadeh A, Werfel T: Participation of complement 3a receptor (C3aR) in the sensitization phase of Th2 mediated allergic contact dermatitis. Exp Dermatol 2012;21: 52-56.

32 Werfel T, Lynch V, Asher A, Tsianakas A, Gupta B, Sarmiento R, et al: A phase 2a proof of concept clinical trial to evaluate ZPL3893787 (ZPL-389), a potent, oral histamine $\mathrm{H} 4$ receptor antagonist for the treatment of moderate to severe atopic dermatitis (AD) in adults. Allergy 2016;71(suppl 102):95 